\title{
Maternal Outcomes Among Hypertensive Pregnant Women at A Tertiary Maternity Hospital in Qatar, 2015-2017: A Case-Control Study
}

\author{
Rayan Itani ${ }^{1}$, Gamal Sayed Ahmed ${ }^{1,2 *}$, Abdullah Ibrahim ${ }^{1}$ and Naela Elmallahi ${ }^{1}$ \\ ${ }^{1}$ Hamad Medical Corporation, Qatar \\ ${ }^{2}$ Weill Cornell Medical College - Qatar, Doha, Qatar \& Dundee Medical School, UK
}

*Corresponding author: Gamal Sayed Ahmed, Department of Obstetrics and Gynecology, Women Wellness and Research Center, Doha, Qatar.
Received Date: April 22, 2019

Published Date: April 30, 2019

\section{Introduction}

Chronic hypertension in pregnancy is associated with increased hospitalization due to new complications or the deterioration of pre-existing comorbidities [1]. Also, there is an increased risk of placental abruption, vascular accidents, gestational diabetes, and C-section [2]. In Qatar, evidence is lacking on the aforementioned issue despite the increasing trend of hypertension and its risk factors. So, we aimed to identify the maternal outcomes among pregnant women with chronic hypertension at a tertiary maternity facility in Doha, Qatar.

\section{Methods}

This was a hospital-based unmatched case-control study among pregnant women attending antenatal follow up at the Women Hospital/ Women Wellness and Research Center (Doha, Qatar) between January 1, 2015 and December 30, 2017. A simple random sampling technique recruited 82 cases (pregnant women with chronic hypertension) and 82 controls (pregnant women without chronic hypertension). Descriptive and inferential statistics were employed as adequate using Wizard Pro (version 1.9.26). A P-value less than 0.05 was considered statistically significant (Graph1\&2).

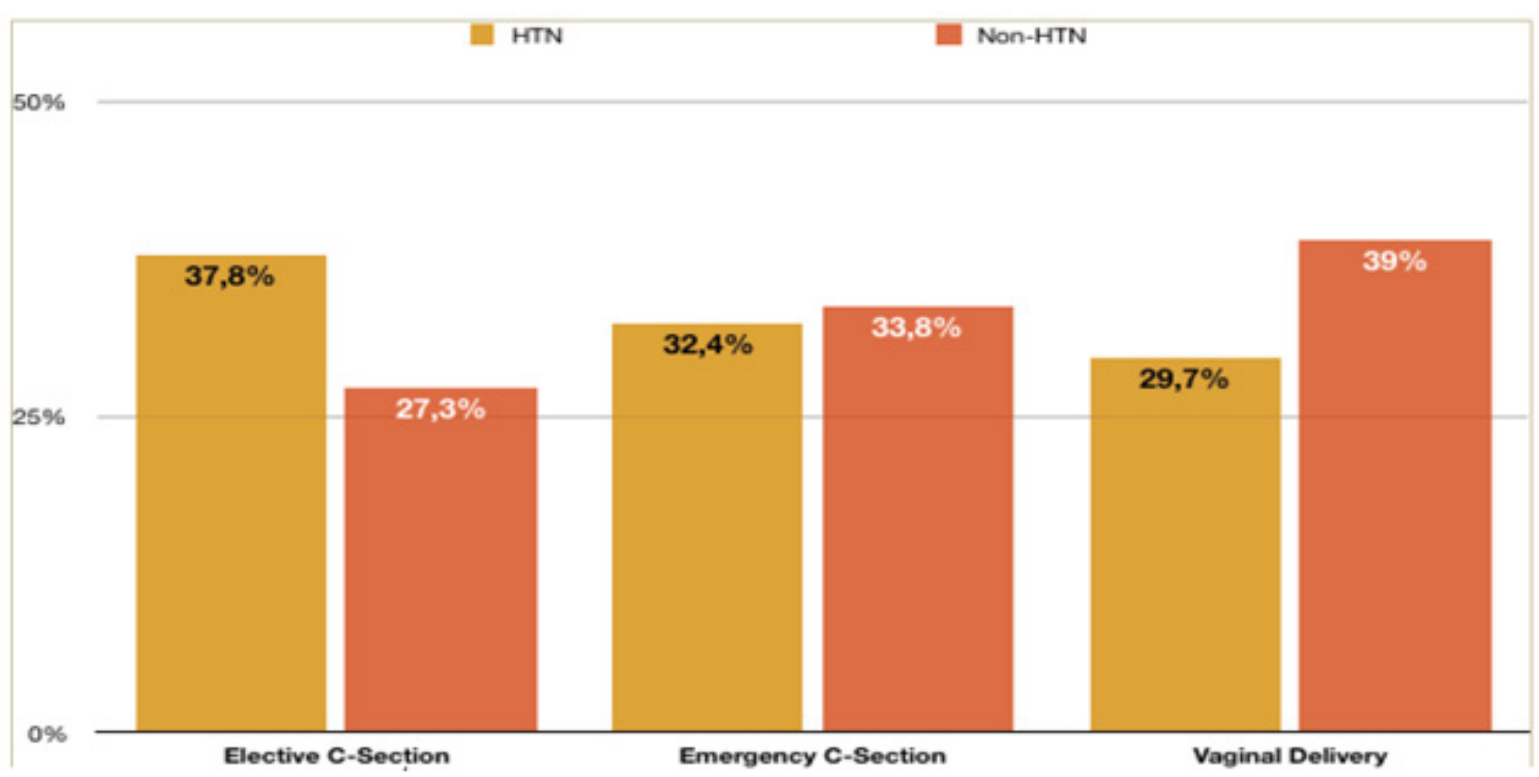

Graph 1: Mode of delivery of both groups. 


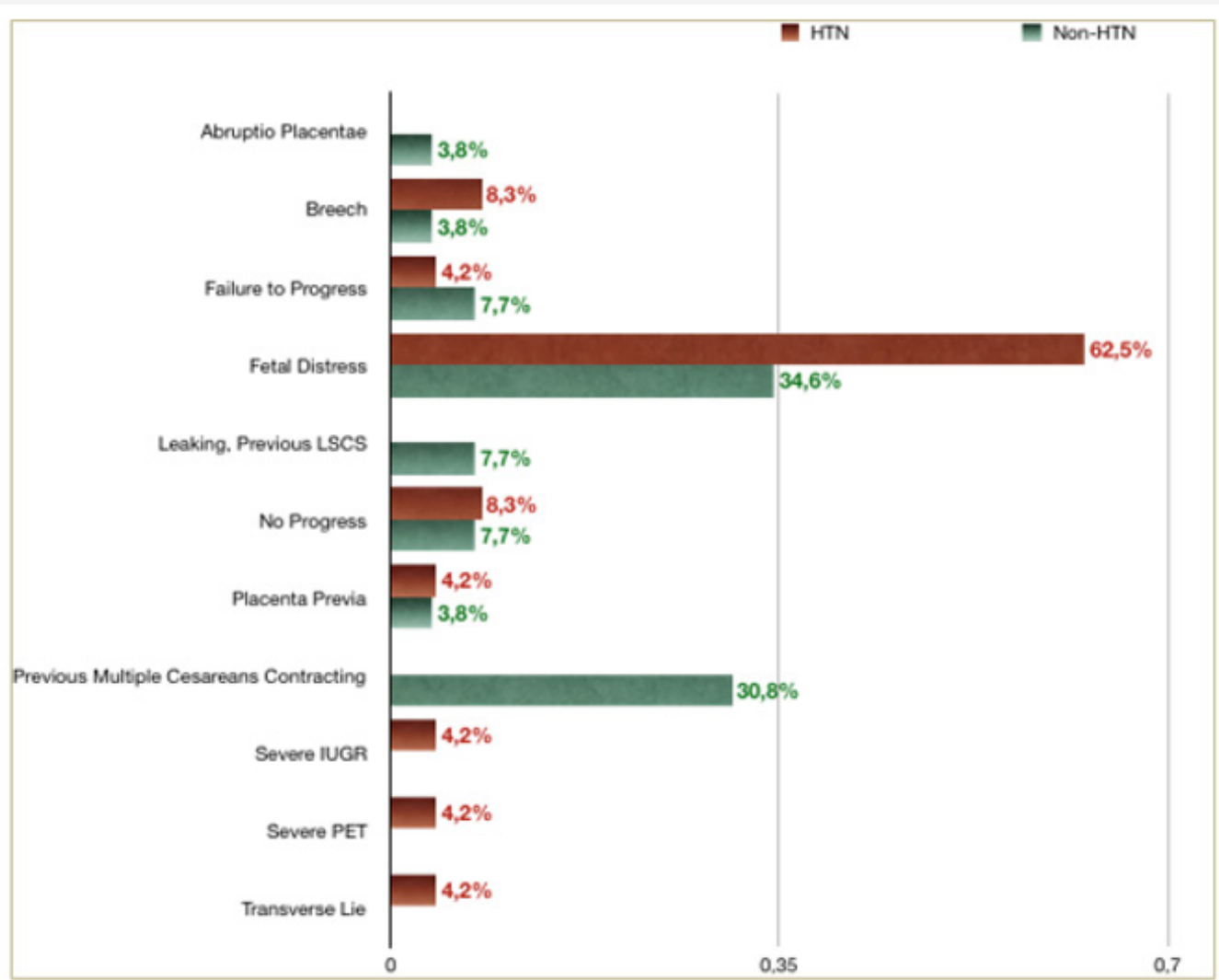

Graph 2: Indications for emergency caesarean section.

\section{Results}

Among the 164 study subjects, the prevalence of gestational diabetes mellitus was higher among hypertensive pregnant women $(14.6 \%)$ than their controls $(11.3 \%)(p=0.54)$. Moreover, the percentage of preeclampsia among cases $(19.5 \%)$ was almost six times higher than that among controls $(3.8 \%)(\mathrm{p}=0.002)$. Thirteen study subjects were lost to follow up (8 cases and 5 controls). Of those remaining, 74 were cases and 77 were controls; the incidence of preterm labor among the cases $(32.4 \%)$ was roughly double that of the controls (16.7\%) (0.002). On the other hand, the incidence of other outcomes (emergency cesarean section, elective cesarean section, vaginal delivery, and fetal distress) was not statistically significant (Table 1).

Table 1: Distribution of maternal outcomes among the cases and controls, WWRC 2015-2017.

\begin{tabular}{|c|c|c|c|}
\hline Variable & HTN (N=82) & Non-HTN (N=82) & P-value \\
\hline GDM (\%) & $14,6 \%$ & $11,3 \%$ & 0,54 \\
\hline PET (\%) & $9,5 \%$ & $3,8 \%$ & 0,002 \\
\hline Preterm labour & $32,4 \%$ & $16,7 \%$ & 0,002 \\
\hline $\begin{array}{c}\text { Emergency Caesarean } \\
\text { Section (\%) }\end{array}$ & $32,4 \%$ & $33,8 \%$ & 0,86 \\
\hline Elective Caesarean (\%) & $37,8 \%$ & $27,3 \%$ & 0,17 \\
\hline Vaginal Delivery (\%) & $29,7 \%$ & $39 \%$ & 0,2 \\
\hline Foetal distress & $20,2 \%$ & $11,7 \%$ & 0,32 \\
\hline
\end{tabular}

\section{Conclusion}

The adverse outcomes associated with hypertension in pregnancy necessitate a more comprehensive clinical management. Further research on the prevention of preterm labor is warranted to optimize the maternal and fetal outcomes of pregnant hypertensive women.

I confirm the originality of the research work and that all fellow authors/researchers of this research work are aware and in agreement of this abstract submission.

\section{Acknowledgement}

None.

\section{Conflict of Interest}

No conflict of interest.

\section{References}

1. Say L, Chou D, Gemmill A, Tunçalp Ö, Moller A, et al. (2014) Global causes of maternal death: a WHO systematic analysis. The Lancet Global Health 2(6): e323-e333.

2. Ferrer R, Sibai B, Mulrow C, Chiquette E, Stevens K, et al. (2000) Management of Mild Chronic Hypertension During Pregnancy. Obstetrics \& Gynecology 96(Supplement): 849-860. 